\title{
Intravenous Dexamethasone and Its Effect on Blood Glucose in Adult Nondiabetic Patients undergoing General Anesthesia for Superficial Surgery
}

\author{
${ }^{1}$ Apeksha A Gala, ${ }^{2}$ Pritee H Bhirud, ${ }^{3}$ Shrividya Chellam
}

\begin{abstract}
Dexamethasone is commonly used for the prevention of postoperative nausea and vomiting (PONV). It also has significant postoperative analgesic benefits. In spite of these advantages, it is seen that intravenous (IV) dexamethasone may affect the blood glucose profile of the patient and healing of wounds. We have studied the effects of IV dexamethasone administered at induction on blood glucose concentrations in adult, nondiabetic patients under general anesthesia (GA) for superficial surgeries, e.g., ear surgeries, breast surgeries, and hernia surgeries.
\end{abstract}

Keywords: Blood glucose concentration, Intravenous dexamethasone, Nondiabetic adult patients, Superficial surgery.

How to cite this article: Gala AA, Bhirud PH, Chellam S. Intravenous Dexamethasone and Its Effect on Blood Glucose in Adult Nondiabetic Patients undergoing General Anesthesia for Superficial Surgery. Res Inno in Anesth 2017;2(2):64-67.

Source of support: Nil

Conflict of interest: Nil

\section{INTRODUCTION}

Intravenous dexamethasone is commonly used for the prevention of PONV. ${ }^{1-3}$ When administered at induction of anesthesia, it has been shown to improve the postoperative pain scores and reduce the need for postoperative analgesics. It is also useful to reduce airway edema, angioedema, cerebral edema, alleviation of nerve damage, inhibition of anaphylactic reactions, and pain of IV propofol administration. ${ }^{4-7}$ Intravenous dexamethasone also has a hyperglycemic effect, which may be compounded by the stress response of surgery via hypothalamo pituitary axis stimulation. This effect may vary according to the

${ }^{1}$ Assistant Professor, ${ }^{2,3}$ Consultant

${ }^{1}$ Department of Anesthesia, Hinduhridaysamrat Balasaheb Thackeray Medical College and Dr. Rustom Narsi Cooper Municipal General Hospital, Mumbai, Maharashtra, India

${ }^{2,3}$ Department of Anesthesia, Bhabha Atomic Research Centre Hospital, Mumbai, Maharashtra, India

Corresponding Author: Apeksha A Gala, Assistant Professor Department of Anesthesia, Hinduhridaysamrat Balasaheb Thackeray Medical College and Dr. Rustom Narsi Cooper Municipal General Hospital, Mumbai, Maharashtra, India, Phone: +912226208894, e-mail: appi.apeksha@gmail.com grade of surgery and has been documented in diabetic as well as in nondiabetic patients undergoing craniotomies, abdominal and gynecological surgeries. ${ }^{8-10}$ We aim to study the effect of dexamethasone, administered at induction for prevention of PONV, on blood glucose profile of nondiabetic patients undergoing superficial surgery.

\section{MATERIALS AND METHODS}

After approval of the institutional review board, 80 American Society of Anesthesiologists (ASA) 1 and 2 patients, who fulfilled inclusion criteria and scheduled to undergo superficial surgery under GA with endotracheal intubation, were included in this prospective randomized double-blind study. Superficial surgeries included otological surgeries, breast surgeries, and hernioplasties . Patients were randomly allotted to two groups by sealed envelope technique. Group I received IV dexamethasone and group II, the control group, received IV ondansetron for PONV. The anesthetist preparing the drugs loaded two syringes per patient. In group I, syringe 1 was filled with $8 \mathrm{mg}$ dexamethasone diluted with saline to a volume of $4 \mathrm{~mL}$ while syringe 2 contained $4 \mathrm{~mL}$ saline. In group II, syringe 1 contained $4 \mathrm{~mL}$ saline while syringe 2 contained injection. ondansetron $0.12 \mathrm{mg} / \mathrm{kg}$ diluted with saline to a volume of $4 \mathrm{~mL}$. The anesthetist conducting the case was blinded to the antiemetic drug administered. Tablet alprazolam $0.25 \mathrm{mg}$ was given to all the patients on the night before surgery and tablet pantoprazole $40 \mathrm{mg}$ on the morning of surgery. Blood glucose level (T0) was checked by a calibrated glucometer (One Touch Ultra Easy glucometer, Johnson \& Johnson) when the patient was taken to the operation theater. Standard monitors were attached and an IV line was secured. Patient was given premedication in the form of IV midazolam $0.05 \mathrm{mg} / \mathrm{kg}$, IV fentanyl 2 to $3 \mu \mathrm{g} / \mathrm{kg}$ followed by induction with IV pentothal sodium 5 to $7 \mathrm{mg} / \mathrm{kg}$ and IV vecuronium $0.1 \mathrm{mg} / \mathrm{kg}$. Four minutes later, intubation was carried out with MacIntosh laryngoscope blade 3 or 4 and Portex cuffed endotracheal tube of appropriate size. Once anesthesia was induced, the syringe labeled syringe no 1 was administered to the patients. Anesthesia was maintained with isoflurane in $\mathrm{O}_{2}$ and $\mathrm{N}_{2} \mathrm{O}$ 40:60. Blood glucose was monitored intraoperatively by the glucometer. The first 
Intravenous Dexamethasone and Its Effect on Blood Glucose

Table 1: Demographic variables

\begin{tabular}{lllllll}
\hline & Mean age & \multicolumn{2}{c}{ Gender } & & \multicolumn{2}{c}{ ASA } \\
\cline { 3 - 5 } Groups & (years) $\pm S D$ & Female & Male & & 1 & 2 \\
\hline I & $43.67 \pm 13.88$ & 22 & 18 & & 29 & 11 \\
II & $47.37 \pm 14.86$ & 26 & 14 & & 26 & 14 \\
\hline Total & $45.52 \pm 14.41$ & 48 & 32 & & 55 & 25 \\
\hline
\end{tabular}

reading was noted, which was $\mathrm{T} 0$, i.e., just before induction. Thereafter, blood glucose was measured every hour, and the readings were noted as: T1 -60 minutes, T2-120 minutes, T3-180 minutes, and T4-240 minutes. All the patients received Ringer's lactate as the IV fluid and blood glucose was controlled with IV human regular insulin only if glucometer reading was $>200 \mathrm{mg} / \mathrm{dL}$. Syringe 2 was administered to the patients 30 minutes before the completion of surgery. Patients in our study were monitored till 4 hours (240 minutes) since superficial surgeries are "day-care" procedures and follow-up beyond 4 hours would have been difficult.

\section{Statistical Analysis}

Data collection and entry were done in Microsoft Excel. Data analysis was done with the help of Statistical Package for the Social Sciences version 19. Mean, standard deviation (SD), median, and interquartile range were applied as tests for quantitative data. Comparison among study groups was done with the help of paired t-test, in the parametric, i.e., measurable data, p-value of less than $5 \%$ was taken as significant.

\section{RESULTS}

A total of 80 patients were studied, 40 each in groups I and II. Table 1 shows the mean age, gender, and ASA status of the patients. The demographic data were comparable between the groups as seen in Table 1 (demographic variables); Table 2 shows the trend of mean blood glucose over time; Graph 1 shows the trend of blood glucose levels in both the groups. Table 2 and Graph 1 show the trend of mean blood glucose levels at 0, 60, 120, 180, and 240 minutes in both groups. The baseline blood glucose level in groups I and II did not differ significantly and were comparable. In group I, the rise in mean blood glucose from baseline was steeper as compared with the rise in mean blood glucose in group II. It was observed that from the first hour after induction, i.e., T1 onward, the mean blood glucose value in group I was significantly higher than the mean blood glucose in group II. These findings are confirmed with the help of Student's t-test for independent samples. The mean blood glucose at baseline and at various intervals was compared within each group as pairs and was analyzed by using paired t-test. The mean blood glucose in group I at 60 minutes was significantly
Table 2: Trend of mean blood glucose over time

\begin{tabular}{lllllll}
\hline \multicolumn{2}{l}{ Groups } & T0 & T1 & $T 2$ & T3 & T4 \\
\hline I & Mean & 101.03 & 124.98 & 136.78 & 143.13 & 151.65 \\
& ISD & 14.919 & 24.339 & 27.577 & 23.436 & 31.126 \\
II & Mean & 102.03 & 112.48 & 115.75 & 113.58 & 112.08 \\
& ISD & 16.178 & 14.622 & 21.215 & 16.421 & 16.114 \\
\multirow{2}{*}{ Total } & Mean & 101.53 & 118.73 & 126.26 & 128.35 & 131.86 \\
& ISD & 15.471 & 20.918 & 26.637 & 25.006 & 31.670 \\
p-value & 0.775 & 0.007 & $<0.001$ & $<0.001$ & $<0.001$ \\
\hline
\end{tabular}

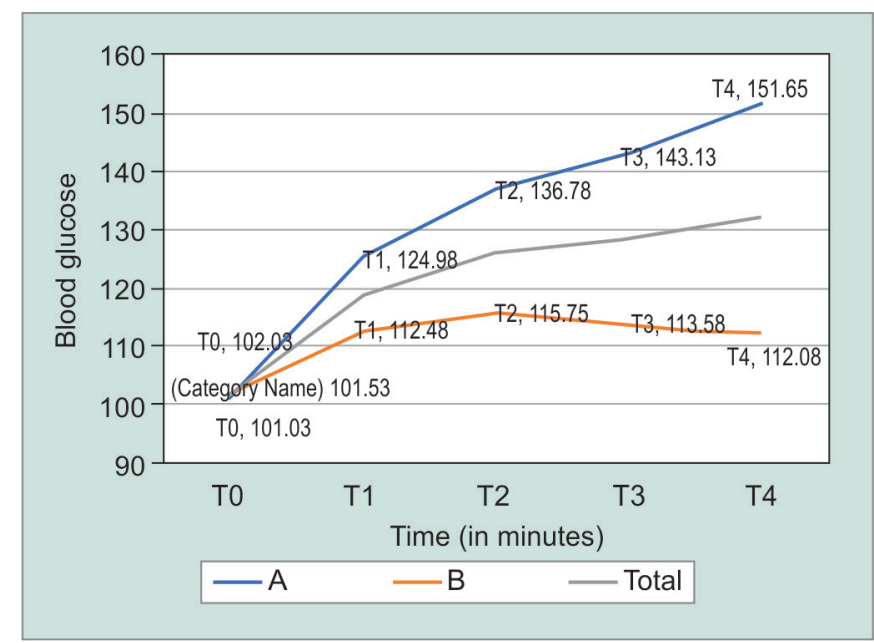

Graph 1: Trend of blood glucose levels in both the groups

raised as compared with the baseline. This significant rise in mean blood glucose was maintained up to 240 minutes in group I while in group II the mean blood glucose started rising significantly only at 180 minutes onward. The highest mean blood glucose was less than $113 \mathrm{mg} / \mathrm{dL}$ in group II and $152 \mathrm{mg} / \mathrm{dL}$ in group I.

\section{DISCUSSION}

We evaluated the blood glucose profile of 80 nondiabetic adult patients undergoing superficial surgery under GA in this randomized, controlled, double-blind study. Our aim was to study the effect of IV dexamethasone on blood glucose levels in these patients. Perioperative blood glucose varied significantly between dexamethasone and control. The difference in blood glucose was appreciable 60 minutes onward after administration of dexamethasone (124 mg/dL in the dexamethasone group and $112 \mathrm{mg} / \mathrm{dL}$ in the control group). This difference in blood glucose despite being significant was never beyond $200 \mathrm{mg} / \mathrm{dL}(152 \mathrm{mg} / \mathrm{dL}-240$ minutes in group I and $115 \mathrm{mg} / \mathrm{dL}-120$ minutes in group II). The safety of dexamethasone prescribed for PONV in the perioperative setting in nondiabetic patients undergoing superficial surgery is emphasized in our study as well. The effect of single low-dose dexamethasone on the blood glucose profile has been studied by investigators varying across 
the perioperative period and across the broad specialties of surgery. The hyperglycemic response seen in major surgeries is attributed to the release of glucagon, epinephrine, and cortisol via hepatic gluconeogenesis and glycogenolysis. ${ }^{11}$ Hence, we included only superficial surgeries to have a minimal or uniform hyperglycemic response. Hans et $\mathrm{al}^{8}$ studied the effects of dexamethasone when given to nondiabetic patients and type II diabetic patients, who underwent abdominal surgery. They found that the blood glucose peaked 120 minutes after dexamethasone in both groups. Contrary to their results, our patients who received dexamethasone showed significantly elevated blood glucose levels 60 minutes onward, which coincided with the peak effect of dexamethasone, whereas in the control group, the ascending trend of blood glucose started 180 minutes onward. This could be because we selected superficial surgeries to minimize the effect of stress on the blood glucose levels and included only nondiabetic patients in our study. Also, our study had a control group, whereas Hans et $\mathrm{al}^{8}$ did not have a control group. They concluded that the percentage increase from the baseline was not different between the diabetic $(25 \%)$ and the nondiabetic patients (30\%). In our study, the highest percentage increase from baseline in group I was $50 \%$ (50 mg/dL), whereas it was $12 \%$ in group II. The patients receiving dexamethasone had a larger percentage increase as compared with the control group. These findings are also in concurrence with Abdelmalak et al. ${ }^{12}$ They observed an increase in the blood glucose concentrations $(86 \mathrm{mg} / \mathrm{dL})$ from the baseline values in patients given dexamethasone, as compared with $(58 \mathrm{mg} / \mathrm{dL})$ the patients who did not receive dexamethasone, all patients being nondiabetic. We observed that there is a rise in the blood glucose concentrations in group I patients, which began at 60 minutes and then increased further, but never beyond $200 \mathrm{mg} / \mathrm{dL}$. This is similar to Abdelmalak et $\mathrm{al}^{12}$ who in their study found an increase in blood glucose from incision to midpoint of surgery after which it attained a steady state. Lukins et $\mathrm{al}^{9}$ studied the effect of dexamethasone given preoperatively, intraoperatively, and none on the blood glucose profiles of nondiabetic patients undergoing craniotomies and found that dexamethasone administered intraoperatively caused the largest increase in blood glucose concentrations above baseline values when compared with the other groups. This is similar to our group I who received dexamethasone at the beginning of surgery. Murphy et $\mathrm{al}^{10}$ conducted a randomized placebo-controlled study in 200 gynecological surgeries where two doses of dexamethasone were administered in two different groups-early and late group and were compared with control. They concluded that the peak blood glucose concentration was similar in the dexamethasone as well as the control group with a peak occurring within 2 to 3 hours and stayed elevated till 8 hours. The difference in the blood glucose profile in their study and ours could be due to the inclusion of gynecological laparoscopic surgeries in the study by Murphy et al. ${ }^{10}$ Bin Wang et $\mathrm{ll}^{13}$ in their meta-analysis on the perioperative effects of dexamethasone concluded that prophylactic dexamethasone administration decreased incidence and severity of PONV during the first postoperative 24 hours. Dexamethasone $8 \mathrm{mg}$ or more was more effective than $5 \mathrm{mg}$ or less in prevention of PONV. Also, this dose of dexamethasone improved the pain scores in the postoperative period reducing the need for postoperative analgesics. Our results are in concurrence with Bin Wang et $\mathrm{al}^{13}$ wherein one patient in group I and two patients in group II had PONV. All three patients had undergone otological surgery. At the time of discharge from recovery room, mean postoperative pain score evaluated by visual analog scale was 2 to 3 in all patients of both groups. Thus, we found that all patients undergoing superficial surgery had an increasing trend of mean blood glucose. This was evident 180 minutes onward in the control group while those who received IV dexamethasone had a steeper rise in blood glucose evident 60 minutes onward and was statistically significant at all intervals thereafter. This hyperglycemic response was evident till 240 minutes after which patients were discharged from the recovery room. The drawback of our study was that we have not studied blood glucose after the patients were shifted to the ward. We have studied only nondiabetic patients and hence further investigation should include diabetics undergoing superficial surgeries. The effect of dexamethasone on blood glucose in patients for surgery under regional anesthesia is worth exploring.

\section{CONCLUSION}

Intravenous dexamethasone administered to prevent PONV significantly increases the blood glucose levels as compared with controls in nondiabetic patients undergoing superficial surgery under GA. Since none of the patients needed treatment for hyperglycemia, dexamethasone should be considered favorably for reduction in PONV and postoperative pain. However, it should be used with caution in those who have deranged blood glucose levels, with timely monitoring of blood glucose.

\section{REFERENCES}

1. Panda NB, Bharadwaj N, Kapoor P, Chari P, Panda NK. Prevention of nausea and vomiting after middle ear surgery: combination of ondansetron and dexamethasone is the right choice. J Otolaryngol 2004 Apr;33(2):88-92.

2. Fujii Y, Numazaki M. Randomized, double-blind comparison of subhypnotic-dose propofol alone and combined with dexamethasone for emesis in parturients undergoing cesarean delivery. Clin Ther 2004 Aug;26(8):1286-1291. 
3. Madan R, Bhatia A, Chakithandy S, Subramaniam R, Rammohan G, Deshpande S, Singh M, Kaul HL. Prophylactic dexamethasone for postoperative nausea and vomiting in pediatric strabismus surgery: a dose ranging and safety evaluation study. Anesth Analg 2005 Jun;100(6):1622-1626.

4. Kaal EC, Vecht CJ. The management of brain edema in brain tumors. Curr Opin Oncol 2004 Nov;16(6):593-600.

5. Lundin A, Magnuson A, Axelsson K, Nilsson O, Samuelsson L. Corticosteroids perioperatively diminishes damage to the C-fibers in microscopic lumbar disc surgery. Spine (Phila Pa 1976) 2005 Nov;30(21):2362-2367.

6. Jamieson NB, Glen P, McMillan DC, McKay CJ, Foulis AK, Carter R, Imrie CW. Systemic inflammatory response predicts outcome in patients undergoing resection for ductal adenocarcinoma head of pancreas. Br J Cancer 2005 Jan;92(1): 21-23.

7. Singh M, Mohta M, Sethi AK, Tyagi A. Efficacy of dexamethasone pretreatment for alleviation of propofol injection pain. Eur J Anaesthesiol 2005 Nov;22(11):888-890.

8. Hans P, Vanthuyne A, Dewandre PY, Brichant JF, Bonhomme V. Blood glucose concentration profile after $10 \mathrm{mg}$ dexamethasone in non-diabetic and type 2 diabetic patients undergoing abdominal surgery. Br J Anaesth 2006 Aug;97(2):164-170.

9. Lukins MB, Manninen PH, Hyperglycemia in patients administered dexamethasone for craniotomy. Anesth Analg 2005 Apr;100(4):1129-1133.

10. Murphy GS, Szokol JW, Avram MJ, Greenberg SB, Shear T, Vender JS, Gray J, Landry E. The effect of single low-dose dexamethasone on blood glucose concentrations in the perioperative period: a randomized, placebo-controlled investigation in gynecologic surgical patients. Anesth Analg 2014 Jun;118(6):1204-1212.

11. Chien-Wei H. Glycemic control in critically ill patients. World J Crit Care Med 2012 Feb;1(1):31-39.

12. Abdelmalak BB, Bonilla AM, Yang D, Chowdary HT, Gottlieb A, Lyden SP, Sessler DI. The hyperglycemic response to major noncardiac surgery and the added effect of steroid administration in patients with and without diabetes. Anesth Analg 2013 May;116(5):1116-1122.

13. Wang B, He K-H, Jiang M-B, Liu C, Min S. Effect of prophylactic dexamethasone on nausea and vomiting after laparoscopic gynecological operation: meta-analysis. Middle East J Anaesthesiol 2011 Oct;21(3):397-402. 